\title{
How do sugars regulate plant growth?
}

\author{
Matthew Paul1,2,3* and Patrick Van Dijck ${ }^{2}$ \\ 1 Plant Science, Rothamsted Research, Harpenden, Hertfordshire, UK \\ 2 VIB Department of Molecular Microbiology, Katholieke Universiteit Leuven, Leuven, Belgium \\ ${ }^{3}$ Laboratory of Molecular Cell Biology, Katholieke Universiteit Leuven, Leuven, Belgium \\ *Correspondence: matthew.paul@rothamsted.ac.uk
}

\section{A commentary on}

Trehalose 6-phosphate: connecting plant metabolism and development

by Ponnu, J., Wahl, V., and Schmid, M. (2011). Front. Plant Sci. 2:70. doi:10.3389/ fpls.2011.00070

Autotrophic organisms synthesize sugars, principally sucrose in the reactions of photosynthesis. This ancient primary process drives the growth and development of all organisms as a source of energy and carbon source. But can sugars actually regulate growth processes themselves beyond just supplying them with the carbon and energy they need? Well, the answer to this question and articulated in the mini review by Ponnu et al. (2011) is an emphatic yes.

Sugars perform diverse functions in living organisms. In plants the pathway that synthesizes the non-reducing disaccharide trehalose, however, has become highly specialized around the signaling function of the precursor of trehalose, trehalose 6-phosphate (T6P). The model that has developed quite rapidly over the last couple of years or so is that T6P signals the availability of sucrose and then through the SnRK1 protein kinase regulatory system orchestrates changes in gene expression that enable sucrose to be used in growth processes. Plants cannot grow, it would seem, without this regulatory system that connects sugars with growth and development. Not only is there regulation of the amount of growth and development by T6P seen in many diverse tissue types, but T6P appears also to control qualitative aspects of growth and development that affect organ form and function such as in inflorescence, leaf, tuber, and seed development.

The authors present the context for trehalose metabolism in plants going back to studies from the early 1980s which reported the surprising toxicity of trehalose when fed in high concentrations to plants. Although only recently appreciated this was actually an indication of the strong regulation on growth processes imparted by T6P. The authors then bring readers up to date with latest knowledge about the numerous trehalose phosphate synthase (TPS) and trehalose phosphate phosphatase (TPP) genes found in plants. A large section in then devoted to the regulation of plant carbohydrate metabolism including impacts on photosynthesis, starch and cell wall metabolism, SnRK1, and the emerging role of the bZIP11 transcription factor in the T6P/SnRK1 regulatory system. Of all the genes involved in the trehalose biosynthetic pathway the specific roles of TPS1 and ra3 TPP are the best characterized and these are described in a final section that emphasizes the importance of the pathway in development. Whilst many questions still remain, for example, what is the function of trehalose itself in plants, what is the role of the many TPS-like genes without apparent catalytic activity and does T6P only function in a cell autonomous fashion or are there specific T6P transporters in the cell? Encouragingly some of the previous barriers to progress are coming down as we understand more about the targets of the pathway, its cell specificity and regulation, and as measurements of T6P become less labor intensive and technically demanding. There is promise too that knowledge of T6P biology in plants will soon deliver into tackling global concerns about food security. Indeed, links between T6P and plant abscisic acid stress hormone signaling as well as the increased photosynthetic capacity upon overexpression of TPS may allow engineering plants that can overcome periods of water shortage and/or result in higher yields under non-optimal conditions.

\section{ACKNOWLEDGMENT}

Rothamsted Research receives strategic funding from BBSRC.

\section{REFERENCE}

Ponnu, J., Wahl, V., and Schmid, M. (2011). Trehalose 6-phosphate: connecting plant metabolism and development. Front. Plant Sci. 2:70. doi:10.3389/ fpls.2011.00070

Received: 14 November 2011; accepted: 15 November 2011; published online: 05 December 2011.

Citation: Paul M and Van Dijck P (2011) How do sugars regulate plant growth? Front. Plant Sci. 2:90. doi: 10.3389/ fpls.2011.00090

This article was submitted to Frontiers in Plant Physiology, a specialty of Frontiers in Plant Science.

Copyright (c) 2011 Paul and Van Dijck. This is an open-access article distributed under the terms of the Creative Commons Attribution Non Commercial License, which permits noncommercial use, distribution, and reproduction in other forums, provided the original authors and source are credited. 